\title{
Degree-hours and Degree-days in Coastal Mediterranean Cities, Patras and Kalamata, Greece
}

Panagiotis Kyriakopoulos ${ }^{1}$, Athanassios Giannopoulos ${ }^{1}$, Yannis G. Caouris ${ }^{1,}{ }^{*}$, Manolis Souliotis ${ }^{2}$, Mattheos Santamouris ${ }^{3}$

1. Department of Mechanical Engineering \& Aeronautics, University of Patras, 26504 Patras, Greece; E-Mails: pkyriakopo@upnet.gr; thgian@upatras.gr; caouris@upatras.gr

2. Department of Chemical Engineering, University of Western Macedonia, Kozani, 50132, Greece; E-Mail: msouliotis@uowm.gr

3. School of Built Environment, University of New South Wales, Sydney, 2052, Australia; E-Mail: m.santamouris@unsw.edu.au

* Correspondence: Yannis G. Caouris; E-Mail: caouris@upatras.gr

Academic Editor: Anthony Brazel

Special Issue: Urban Heat Island Effect

Adv Environ Eng Res

2021, volume 2 , issue 4

doi:10.21926/aeer.2104032
Received: September 04, 2021

Accepted: November 17, 2021

Published: December 06, 2021

\begin{abstract}
The hourly ambient air temperature information was analyzed for two Greek coastal Mediterranean cities: Patras (for the entire 2018 year) with ten urban and one rural stations, and Kalamata (for the entire 2019 and 2020 years) with eight urban and two rural stations. The heating and cooling Degree Hours (DH) and Degree Days (DD) were calculated, for base temperatures of $18{ }^{\circ} \mathrm{C}$ and $26^{\circ} \mathrm{C}$, respectively. The urban heating degree hours for the cities of Patras and Kalamata were observed to be $19.2 \%$ and $24 \%$, respectively, lower than that of the rural areas. Similarly, the urban cooling degree hours for the two cities were $9 \%$ and $22 \%$ higher than that of rural areas. These findings indicate a distinct urban heat island effect in both the cities, with greater effects in Kalamata than in Patras. Following comparisons with historical data from reliable sources, it could be observed that summers are trending warmer and winters are trending milder.
\end{abstract}

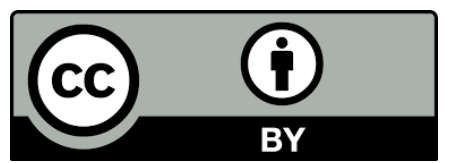

(C) 2021 by the author. This is an open access article distributed under the conditions of the Creative Commons by Attribution License, which permits unrestricted use, distribution, and reproduction in any medium or format, provided the original work is correctly cited. 


\section{Keywords}

Heating degree-hours; Heating degree-days; Cooling degree-hours; Cooling degree-days; Urban heat island; Kalamata; Patras.

\section{Introduction}

Various techniques, including simple steady-state models to comprehensive dynamic simulation approaches, have been successfully used for assessing the energy demands to heat or cool a building. Most of the dynamic simulation tools available in the market are often challenging to operate [1] since they demand a significant number of various input parameters such as analytical meteorological data, lighting profiles, the quantity and schedule of occupants, and so on [2]. These factors make them inappropriate for widespread applications, especially in preliminary evaluation of the energy requirements of buildings [3]. Conversely, simple steady-state models require minimal data (typically only hourly or daily weather data) and maintain satisfactory accuracy in estimating the energy consumption of buildings, as long as the building usage and the efficiency of heating ventilation and air conditioning system are maintained constant. The traditional and variable-base degree-day (DD) or degree-hour (DH) techniques are the most recognized methods of these steadystate models [1]. The thermal and cooling energy consumption of buildings has been estimated primarily by the DD approach [4], which is a basic and easy method for preliminary energy audits, providing acceptable accuracy in the estimation of energy consumption of a building $[5,6]$. DD refers to the difference between the outdoor mean temperature during 24 hours and a specific base temperature $\left(T_{b}\right)[7]$. The latter represents the outdoor air temperature at which heating or cooling systems are not required to satisfy people. The calculated DD is regarded as heating degree day (HDD), when the mean daily ambient air temperature is less than heating base temperature, and as Cooling Degree Day (CDD) when it is greater than the cooling base temperature. As a reason, the indoor/outdoor air exchange through windows and doors and the total heat gains from inhabitants, lighting, equipment, and solar radiation should be considered to determine base temperature $[6,8$, 9]. The anticipated outputs can be applied to enhance the overall energy efficiency of buildings and identify the most effective solutions to minimize the energy consumption of buildings [10]. The Technical Guideline (TG) of the Technical Chamber of Greece (TCG) adopts base temperatures of $18{ }^{\circ} \mathrm{C}$ and $26^{\circ} \mathrm{C}$ for calculating HDD and CDD, respectively [11], which correspond to acceptable comfort temperatures during winter and summer in Greece $[8,11,12]$. For areas with hourly temperature data, the degree-hour $(\mathrm{DH})$ approach can be used to estimate the energy requirements of a building more precisely rather than the DD method. The DH method is defined as identical to the DD method. When the mean hourly ambient air temperature is less than the heating base temperature, the estimated $\mathrm{DH}$ is heating degree hour $(\mathrm{HDH})$. In contrast, when it is greater than the cooling base temperature, it is called cooling degree hour $(\mathrm{CDH})[11,13]$. Aside from estimating the energy demand of a building, DDs and DHs are frequently employed as climatic indicators for assessing climate change impacts, especially the increasing outdoor temperature [9]. Although these methodologies are obsolete, they are nevertheless widely applied to predict the energy consumption of buildings and climate change trends. Harvey (2020) [8] examined the application of HDD and CDD methods to estimate heating and cooling loads of buildings and proposed acceptable 
reference temperatures. Spinoni et al. (2018) [14] a Iso applied HDD-CDD indicators to investigate whether energy demands for cooling and heating of buildings are projected to rise or fall due to climate change. Similarly, Andrade et a I. (2021) [15] also investigated climate change scenarios in Portugal using HDD-CDD indicators. Ramon et al. (2020) calculated the HDD and CDD in the context of the recent past and near future high-end climate change scenario (RCP 8.5) in Belgium.

Many researchers have reported the Mediterranean region as one of the most vulnerable areas to the projected climate change [14-20]. The current climate projections predict extreme weather events in the region in response to the warmer and drier periods in the near future. Hence, it is critical to research the climate conditions of metropolitan areas with frequent heatwaves. The coastal cities are highly influenced by climate due to their proximity to the sea and are unique. The current study examines the urban and rural values of HDHs CDHs, HDDs, and CDDs for two coastal Mediterranean cities, Patras and Kalamata. Both cities have high levels of urban heat island intensity (UHI), with higher levels in Kalamata. The variable-base DD or DH approaches are applied here as an extension of the classic approach, and the results are compared with relevant information from past years. The monthly DDs and DHs for most Greek cities are reported by TG 20701-3/2010 (2014) of TCG [11] and Papakostas et al. a,b [21, 22]. In the former study, HDDs and CDHs statistics are published for 62 and 30 Greek cities, respectively, whereas HDDs and CDDs for 50 Greek cities are reported in the latter. The mean monthly ambient temperature was used to formulate an equation for the estimation of HDD (equation 9 in section 2) and mean hourly ambient temperatures of each monthly mean day were used to formulate the equation to estimate $\mathrm{CDHs}$ (equation 11 in section 2) [11]. Papakostas et al. a,b [21, 22] calculated HDDs and CDDs for 48 cities, including Patras and Kalamata by Erb's method [23], using the monthly average ambient temperature of several years. The authors used a statistical algorithm with the accuracy of $5 \% \div 10.5 \%$ for calculations of HDDs [21] and $0.1 \% \div 11 \%$ for CDDs [22].

\section{Methods of Calculation}

Various techniques for estimating HDDs, CDDs, HDHs, and CDHs have been proposed, with the hourly method being the most accurate, which requires hourly temperature data. This method estimates the degree-hours by adding the differences between base temperature and hourly average ambient air temperature. The daily HDHs and CDHs can be defined by equations (1) and (2), respectively.

$$
\begin{aligned}
& H D H_{d}=\sum_{i=1}^{24}\left(T_{b}-T_{i}\right)^{+} \\
& C D H_{d}=\sum_{i=1}^{24}\left(T_{i}-T_{b}\right)^{+}
\end{aligned}
$$

Where ' $T_{b}$ ' is the base temperature, and ' $T_{i}$ ' is the ambient air temperature at the $i^{\text {th }}$ hour of the day.

Similarly, the number of daily HDDs and CDDs can be defined by equations (3) and (4), respectively. 


$$
\begin{aligned}
H D D_{d} & =\frac{\sum_{i=1}^{24}\left(T_{b}-T_{i}\right)^{+}}{24} \\
C D D_{d} & =\frac{\sum_{i=1}^{24}\left(T_{i}-T_{b}\right)^{+}}{24}
\end{aligned}
$$

The number of monthly heating and cooling DHs/DDs can be calculated by adding the daily DDs /DHs over a specific period of time and can be defined by equations (5) and (6), respectively. The number of annual heating and cooling DHs/DDs is calculated by summing up the monthly DHs/DDs over the period and can be defined by equations (7) and (8), respectively.

$$
\begin{aligned}
& D H_{m}=\sum_{j=1}^{N} D H_{d, j} \\
& D D_{m}=\sum_{j=1}^{N} D D_{d, j}
\end{aligned}
$$

Where ' $\mathrm{N}$ ' denotes the number of days per month and ' $D H_{d, j}{ }^{\prime}$ and ' $D D_{d, j}$ ' represent the daily $\mathrm{DHs}$ and DDs of the $\mathrm{j}^{\text {th }}$ day of the month.

$$
\begin{aligned}
& D H_{a}=\sum_{k=1}^{12} D H_{m, k} \\
& D D_{a}=\sum_{k=1}^{12} D D_{m, k}
\end{aligned}
$$

Where ' $D H_{m, k}$ ' and ' $D D_{a}$ ' represent the monthly DHs and DDs of the $\mathrm{k}^{\text {th }}$ month of the year.

In areas where hourly temperature data is unavailable, the calculation of the HDHs or HDDs of a month can be carried out using equation (9) [11], which is given below.

$$
H D D_{m}=\sum\left[N_{m}\left(T_{b}-T_{m}\right)^{+}\right]
$$

Where ' $\mathrm{N}_{\mathrm{m}}$ ', ' $\mathrm{T}_{\mathrm{b}}$ ' and ' $\mathrm{T}_{\mathrm{m}}$ ' represent is the number of days in a month, base temperature $\left(18^{\circ} \mathrm{C}\right)$ and the mean monthly ambient air temperature, respectively.

Similarly, the monthly CDDs can be calculated using the equation (10) and CDHs can be calculated, as per the guidelines [11] using the equation (11), and are as follows.

$$
\begin{gathered}
C D D_{m}=\sum\left[N_{m}\left(T_{m}-T_{b}\right)^{+}\right] \\
C D H_{m}=\sum\left[N_{m} \sum_{i}\left(T_{b}-T_{i m}\right)^{+}\right]
\end{gathered}
$$


Where ' $\mathrm{T}_{\mathrm{b}}$ ' is the base temperature $\left(26^{\circ} \mathrm{C}\right)$, and ' $\mathrm{T}_{\mathrm{im}}$ ' is the mean hourly ambient air temperature in the $\mathrm{m}^{\text {th }}$ month of the year. Only positive parameters are used in these equations $(1,2,3,4,9,10$, 11) which is indicated by a 't' power.

\section{Description of the Cities and Measuring Networks}

Patras $\left(38^{\circ} 15^{\prime} \mathrm{N}, 21^{\circ} 45^{\prime} \mathrm{E}\right.$ ) is the capital of Western Greece and is a medium-sized city with a population of over 200,000 people. With a population of about 70,000 people, Kalamata $\left(37^{\circ} 2^{\prime} \mathrm{N}, 22^{\circ} 7^{\prime} \mathrm{E}\right)$ is the second populous city in the Peloponnese area. The relative locations of the two cities are shown in the following Figure 1.

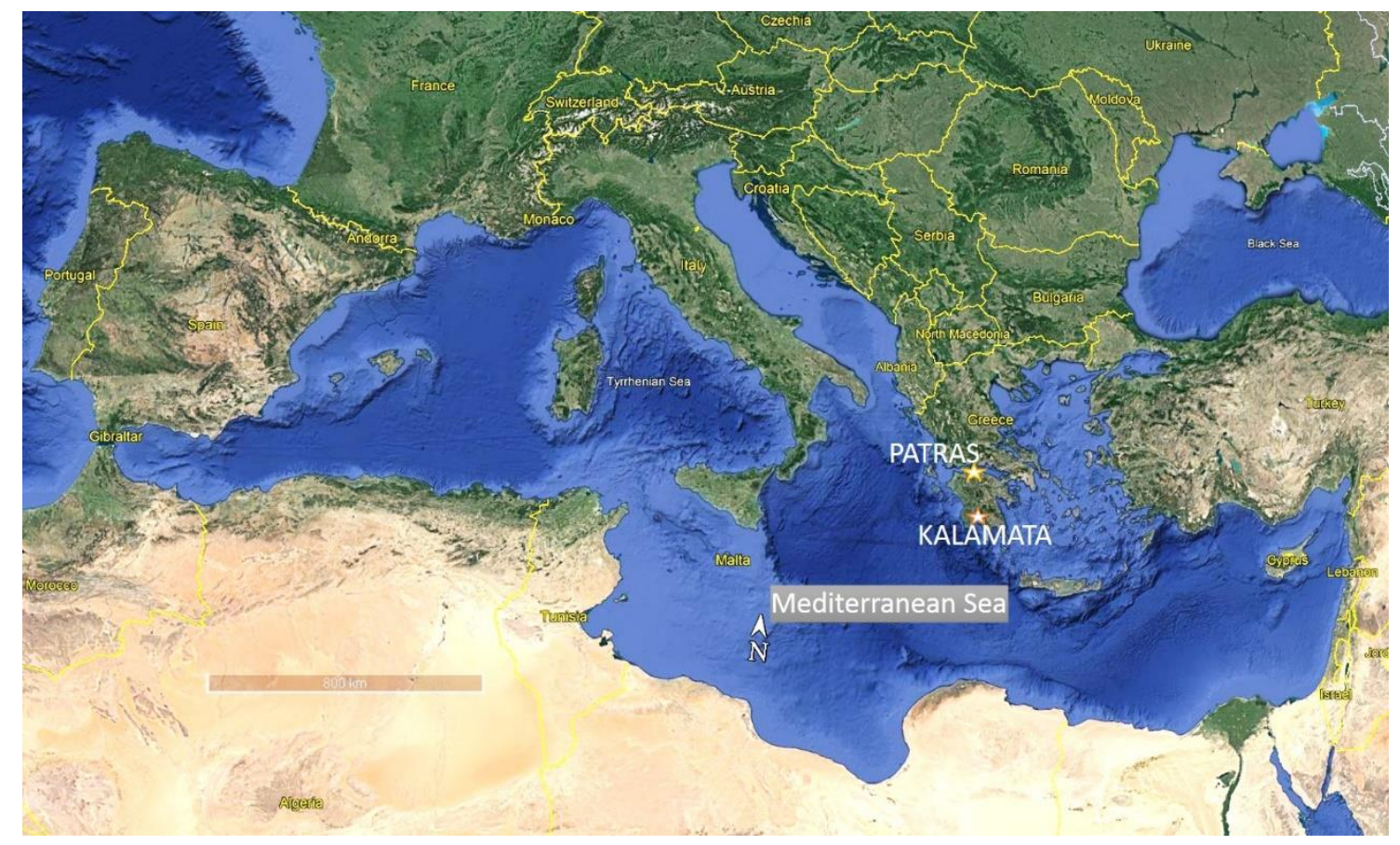

Figure 1 Locations of Patras and Kalamata cities (terrain view by Google Earth 2021).

As part of the study, suitable sites were identified in both the cities to install twenty-one temperature monitoring and logging stations, among which ten were in the urban areas of Patras, one in the rural area of Patras (Agios Vasileios $\sim 10 \mathrm{~km}$ from the city center), eight in the urban area of Kalamata and the remaining two in the rural areas of Antikalamos (inland, $\sim 5 \mathrm{~km}$ from the city center) and Verga (near seashore, $\sim 5.5 \mathrm{~km}$ from the city center). The stations in the two study sites were placed at $4 \div 4.5 \mathrm{~m}$ and $4 \div 5 \mathrm{~m}$ respectively from the ground. A general view of Patras and Kalamata and the locations of monitoring stations are shown in Figure 2 and Figure 3, respectively. The devices were placed inside white cages (radiation shields), with lateral gaps (similar to the Stevenson screen), to protect them from solar or thermal radiation and rain. 


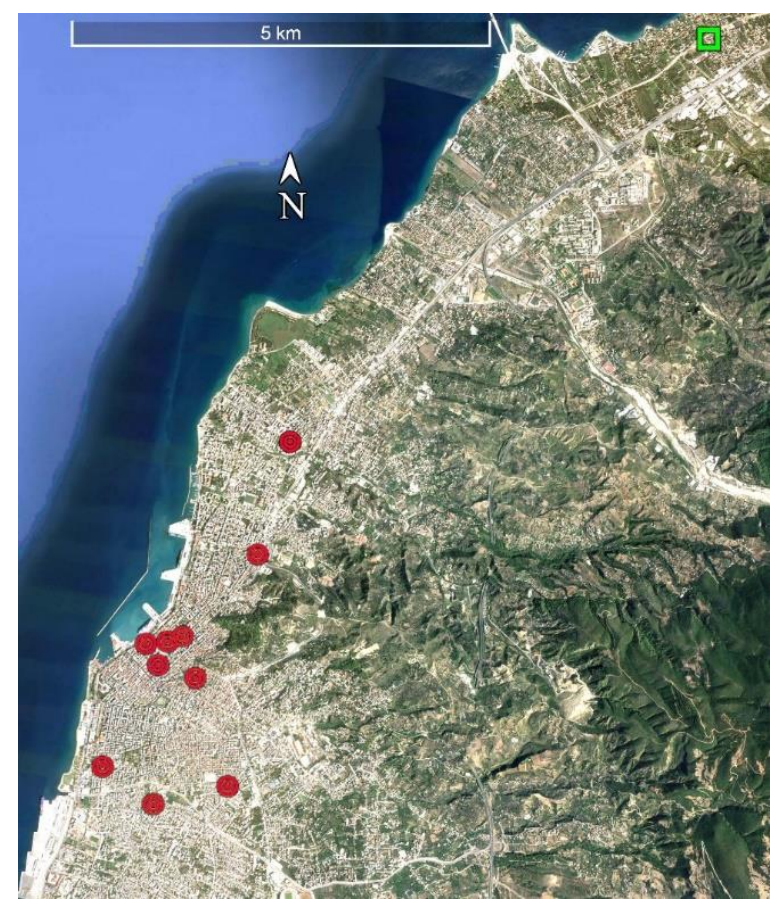

Figure 2 General view of Patras city. Red circles mark the locations of the ten urban monitoring stations and green rectangle the rural monitoring station (terrain view by Google Earth 2021).

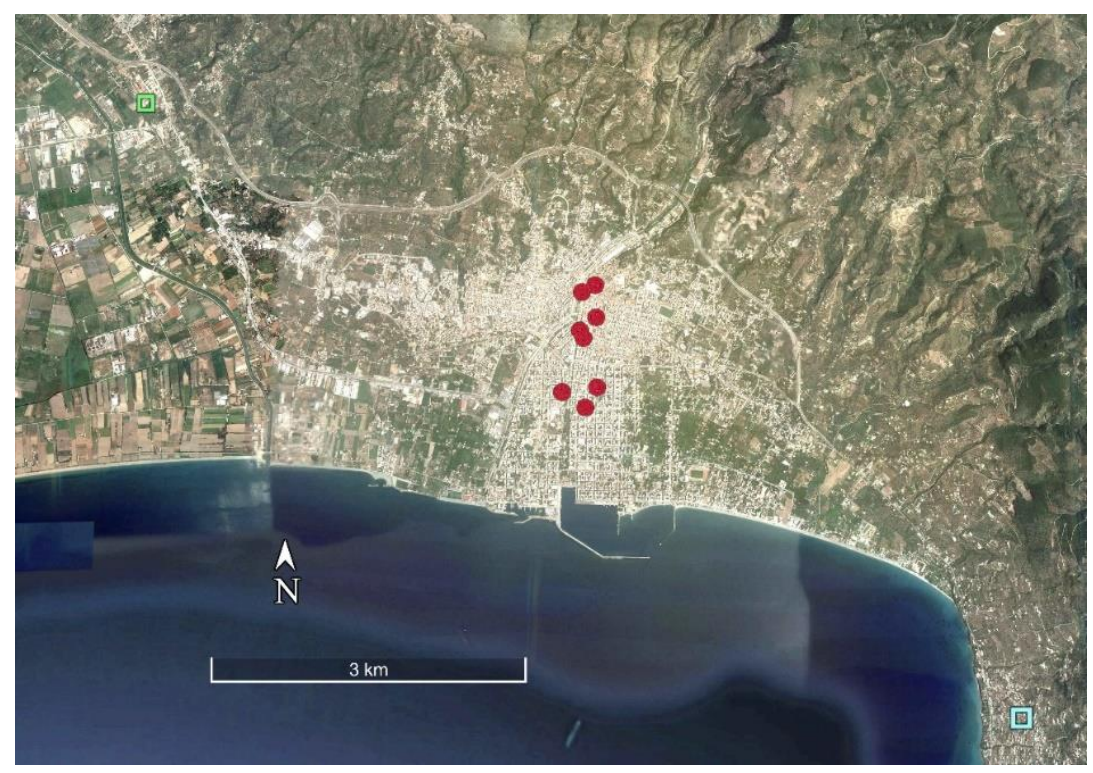

Figure 3 General view of Kalamata city. Red asterisks mark the locations of the eight urban monitoring stations. The inland and near sea stations are marked with green and cyan rectangles, respectively (terrain view by Google Earth 2021).

The temperature measurements were recorded for every hour. The period of data collection for Patras was the year 2018 and that for kalamata was 2019 and 2020 full years Functional range of devices installed in Patras was $-40^{\circ} \mathrm{C}$ to $+85^{\circ} \mathrm{C}$, with sensor accuracy of $\pm 0.2{ }^{\circ} \mathrm{C}$, (range from $0{ }^{\circ} \mathrm{C}$ to $70{ }^{\circ} \mathrm{C}$ ) and resolution of $0.4{ }^{\circ} \mathrm{C}$. Similarly, the devices used in Kalamata city had a functional range from -30 to $70{ }^{\circ} \mathrm{C}$ with a sensor accuracy of $\pm 0.5^{\circ} \mathrm{C}$ and resolution of $0.1{ }^{\circ} \mathrm{C}$. The hourly recorded 
temperature data were used to compute the monthly $\mathrm{HDHs}$ and $\mathrm{CDHs}$ of each station for the base temperatures of $18{ }^{\circ} \mathrm{C}$ and $26^{\circ} \mathrm{C}$, respectively, using equation 5 .

\section{Results and Discussion}

The urban values are calculated as the average value of all urban stations, and the rural values for Kalamata represent the average value of the two rural stations and are shown in Tables 4 and 6. The estimated results of HDHs, HDDs, CDHs, and CDDs for Patras and Kalamata for different years are presented in separate Tables $1,2,3,4,5$, and 6.

Table 1 The monthly HDHs, HDDs, CDHs, and CDDs of the urban areas of Patras for the year 2018.

\begin{tabular}{lllll}
\hline & HDHs & HDDs & CDHs & CDDs \\
Month & & & & \\
\hline January & $6,548.71$ & 272.86 & - & - \\
February & $4,532.48$ & 188.85 & - & - \\
March & $3,430.11$ & 142.92 & - & - \\
April & $1,141.98$ & 47.58 & 5.91 & 0.25 \\
May & 324.54 & 13.52 & 332.76 & 13.87 \\
June & 12.46 & 0.52 & $1,303.59$ & 54.32 \\
July & - & - & $2,190.45$ & 91.27 \\
August & - & - & $2,093.91$ & 87.25 \\
September & 5.89 & 0.25 & 702.95 & 29.29 \\
October & 309.88 & 12.91 & 46.86 & 1.95 \\
November & $2,737.96$ & 114.08 & 0.9 & 0.04 \\
December & $4,065.50$ & 169.40 & - & - \\
Yearly & $\mathbf{2 3 , 1 0 9 . 5 1}$ & $\mathbf{9 6 2 . 9 0}$ & $\mathbf{6 , 6 7 7 . 3 3}$ & $\mathbf{2 7 8 . 2 2}$ \\
\hline
\end{tabular}

Table 2 The monthly HDHs, HDDs, CDHs, and CDDs of the rural stations of Patras for the year 2018.

\begin{tabular}{lllll}
\hline & HDHs & HDDs & CDHs & CDDs \\
Month & & & & \\
\hline January & $7,603.90$ & 316.83 & - & - \\
February & $5,490.10$ & 228.75 & - & - \\
March & $4,607.00$ & 191.96 & - & - \\
April & $1,745.10$ & 72.71 & 7.60 & 0.32 \\
May & 566.80 & 23.62 & 255.20 & 10.63 \\
June & 63.50 & 2.65 & $1,121.30$ & 46.72 \\
\hline
\end{tabular}




\begin{tabular}{lllll}
\hline July & - & - & $2,073.20$ & 86.38 \\
August & - & - & $1,701.30$ & 70.89 \\
September & 35.50 & 1.48 & 759.90 & 31.66 \\
October & 528.70 & 22.03 & 159.60 & 6.65 \\
November & $3,300.00$ & 137.50 & - & - \\
December & $4,664.80$ & 194.37 & - & - \\
Yearly & $\mathbf{2 8 , 6 0 5 . 4 0}$ & $\mathbf{1 , 1 9 1 . 8 9}$ & $\mathbf{6 , 0 7 8 . 1 0}$ & $\mathbf{2 5 3 . 2 5}$ \\
\hline
\end{tabular}

Table 3 The monthly HDHs and HDDs of the urban areas of Kalamata for the years 2019 and 2020.

\begin{tabular}{lllllll}
\hline & HDHs & & \multicolumn{3}{l}{ HDDs } \\
Year & 2019 & 2020 & $\begin{array}{l}\text { Average } \\
\text { 2019-2020 }\end{array}$ & 2019 & 2020 & $\begin{array}{l}\text { Average } \\
\text { Month }\end{array}$ \\
\hline January & $5,716.13$ & $4,457.40$ & $5,086.76$ & 238.17 & 185.72 & 211.95 \\
February & $3,769.77$ & $3,214.95$ & $3,492.36$ & 157.07 & 133.96 & 145.51 \\
March & $2,620.02$ & $2,372.90$ & $2,496.46$ & 109.17 & 98.87 & 104.02 \\
April & $1,439.98$ & $1,407.60$ & $1,423.79$ & 60.00 & 58.65 & 59.32 \\
May & 533.97 & 223.74 & 378.85 & 22.25 & 9.32 & 15.79 \\
June & 15.58 & 25.30 & 20.44 & 0.65 & 1.05 & 0.85 \\
July & - & - & - & - & - & - \\
August & - & - & - & - & - & - \\
September & - & - & - & - & - & - \\
October & $\mathbf{8 . 0 4}$ & 139.21 & 73.62 & 0.34 & 5.80 & 3.07 \\
November & 653.54 & $1,020.97$ & 837.26 & 27.23 & 42.54 & 34.89 \\
December & $\mathbf{2 , 7 6 7 . 0 8}$ & $\mathbf{2 , 3 2 9 . 4 5}$ & $\mathbf{2 , 5 4 8 . 2 6}$ & 115.30 & 97.06 & 106.18 \\
Yearly & $\mathbf{1 7 , 5 2 4 . 1 0}$ & $\mathbf{1 5 , 1 9 1 . 5 1}$ & & $\mathbf{7 3 0 . 1 7}$ & $\mathbf{6 3 2 . 9 8}$ & \\
Avg. Yearly & & & $\mathbf{1 6 , 3 5 7 . 8 0}$ & & & $\mathbf{6 8 1 . 5 8}$ \\
\hline
\end{tabular}

Table 4 The monthly HDHs and HDDs of the rural area of Kalamata for the years 2019 and 2020.

\begin{tabular}{lllllll}
\hline & HDHs & \multicolumn{5}{c}{ HDDs } \\
$\begin{array}{l}\text { Year } \\
\text { Month }\end{array}$ & 2019 & 2020 & $\begin{array}{l}\text { Average } \\
\text { 2019-2020 }\end{array}$ & 2019 & 2020 & $\begin{array}{l}\text { Average } \\
\text { 2019-2020 }\end{array}$ \\
\hline January & $6,182.52$ & $5,494.49$ & $5,838.50$ & 257.60 & 228.94 & 243.27 \\
February & $4,284.24$ & $3,960.11$ & $4,122.17$ & 178.51 & 165.00 & 171.76 \\
March & $3,449.47$ & $3,130.63$ & $3,290.05$ & 143.73 & 130.44 & 137.09 \\
April & $2,008.73$ & $2,116.20$ & $2,062.47$ & 83.70 & 88.18 & 85.94 \\
May & $1,000.13$ & 603.07 & 801.60 & 41.67 & 25.13 & 33.40 \\
\hline
\end{tabular}




\begin{tabular}{lllllll}
\hline June & 95.77 & 130.74 & 113.26 & 3.99 & 5.45 & 4.72 \\
July & 0.11 & - & 0.05 & - & - & - \\
August & - & - & - & - & - & - \\
September & 9.55 & 13.00 & 11.28 & 0.40 & 0.54 & 0.47 \\
October & 323.12 & 587.24 & 455.18 & 13.46 & 24.47 & 18.97 \\
November & $1,308.25$ & $1,871.40$ & $1,589.83$ & 54.51 & 77.98 & 66.24 \\
December & $3,525.97$ & $\mathbf{2 , 9 7 7 . 1 3}$ & $3,251.55$ & 146.92 & 124.05 & 135.48 \\
Yearly & $\mathbf{2 2 , 1 8 7 . 8 7}$ & $\mathbf{2 0 , 8 8 4 . 0 1}$ & & $\mathbf{9 2 4 . 4 9}$ & $\mathbf{8 7 0 . 1 7}$ & \\
Avg. Yearly & & & $\mathbf{2 1 , 5 3 5 . 9 4}$ & & & $\mathbf{8 9 7 . 3 3}$ \\
\hline
\end{tabular}

Table 5 The monthly CDHs and CDDs of the urban area of Kalamata for the years 2019 and 2020.

\begin{tabular}{|c|c|c|c|c|c|c|}
\hline & $\mathrm{CDHs}$ & & & CDDs & & \\
\hline $\begin{array}{l}\text { Year } \\
\text { Month }\end{array}$ & 2019 & 2020 & $\begin{array}{l}\text { Average } \\
\text { 2019-2020 }\end{array}$ & 2019 & 2020 & $\begin{array}{l}\text { Average } \\
\text { 2019-2020 }\end{array}$ \\
\hline January & - & - & - & - & - & - \\
\hline February & - & - & - & - & - & - \\
\hline March & 0.19 & 0.29 & 0.24 & 0.01 & 0.01 & 0.01 \\
\hline April & 37.18 & 8.39 & 22.78 & 1.55 & 0.35 & 0.95 \\
\hline May & 99.77 & 640.90 & 370.34 & 4.16 & 26.70 & 15.43 \\
\hline June & $1,558.18$ & 745.59 & $1,151.88$ & 64.92 & 31.07 & 48.00 \\
\hline July & $2,491.84$ & $2,339.05$ & $2,415.45$ & 103.83 & 97.46 & 100.64 \\
\hline August & $2,813.92$ & $2,510.53$ & $2,662.23$ & 117.25 & 104.61 & 110.93 \\
\hline September & $1,237.28$ & $1,405.49$ & $1,321.38$ & 51.55 & 58.56 & 55.06 \\
\hline October & 320.02 & 322.82 & 321.42 & 13.33 & 13.45 & 13.39 \\
\hline November & 10.10 & 1.50 & 5.80 & 0.42 & 0.06 & 0.24 \\
\hline December & - & - & - & - & - & - \\
\hline Yearly & $8,568.48$ & $7,974.55$ & & 357.02 & 332.27 & \\
\hline Avg. Yearly & & & $8,271.51$ & & & 344.65 \\
\hline
\end{tabular}

Table 6 The monthly CDHs and CDDs for the rural areas of Kalamata for the years 2019 and 2020.

\begin{tabular}{|c|c|c|c|c|c|c|}
\hline & $\mathrm{CDHs}$ & & & CDDs & & \\
\hline $\begin{array}{l}\text { Year } \\
\text { Month }\end{array}$ & 2019 & 2020 & $\begin{array}{l}\text { Average } \\
2019-2020\end{array}$ & 2019 & 2020 & $\begin{array}{l}\text { Average } \\
\text { 2019-2020 }\end{array}$ \\
\hline January & - & - & - & - & - & - \\
\hline February & - & - & - & - & - & - \\
\hline March & - & - & - & - & - & - \\
\hline
\end{tabular}




\begin{tabular}{lllllll} 
April & 21.16 & 2.51 & 11.83 & 0.88 & 0.10 & 0.49 \\
May & 70.13 & 483.45 & 276.79 & 2.92 & 20.14 & 11.53 \\
June & $1,264.98$ & 587.70 & 926.34 & 52.71 & 24.49 & 38.60 \\
July & $2,083.21$ & $1,969.36$ & $2,026.28$ & 86.80 & 82.06 & 84.43 \\
August & $2,407.63$ & $2,119.85$ & $2,263.74$ & 100.32 & 88.33 & 94.32 \\
September & $1,032.25$ & $1,137.74$ & $1,085.00$ & 43.01 & 47.41 & 45.21 \\
October & 186.02 & 192.89 & 189.45 & 7.75 & 8.04 & 7.89 \\
November & 4.44 & - & 2.22 & 0.19 & - & 0.09 \\
December & - & - & - & - & - & - \\
Yearly & $\mathbf{7 , 0 6 9 . 8 1}$ & $\mathbf{6 , 4 9 3 . 4 9}$ & & $\mathbf{2 9 4 . 5 8}$ & $\mathbf{2 7 0 . 5 6}$ & \\
Avg. Yearly & & & $\mathbf{6 , 7 8 1 . 6 5}$ & & & $\mathbf{2 8 2 . 5 7}$ \\
\hline
\end{tabular}

The hourly recorded temperatures of each monitoring station for base temperatures of $18{ }^{\circ} \mathrm{C}$ and $26^{\circ} \mathrm{C}$ were used to calculate the monthly $\mathrm{HDH}$ s and $\mathrm{CDHs}$, respectively, using equation (5). The $\mathrm{HDHs}$ and $\mathrm{CDHs}$ for the urban areas are calculated from the average $\mathrm{HDHs}$, and $\mathrm{CDH}$ s collected from corresponding urban stations. The HDDs and CDDs are calculated by dividing HDHs and CDHs by 24 (equations 3, 4).

The urban zones of Patras are observed to have 5,495.89 HDHs lesser than the rural areas approximating a 19.2\% reduction (Tables 1 and 2), which is close to the early estimate of $22.3 \%$ by Caouris et al. [24]. Similarly, the $\mathrm{CDH}$ s in the urban areas are also $9 \%$ higher than those in the rural areas, indicating the UHI effect. Table 7 clearly shows that January is the coldest month, and this finding is substantiated by previous studies $[11,21]$. As shown in Table 7 , the findings suggest that July is the warmest month, which contradicts the findings provided by AUTh [22], which reports August month as the warmest. However, the CDHs or CDD statistics for Patras city are not reported by TCG [11].

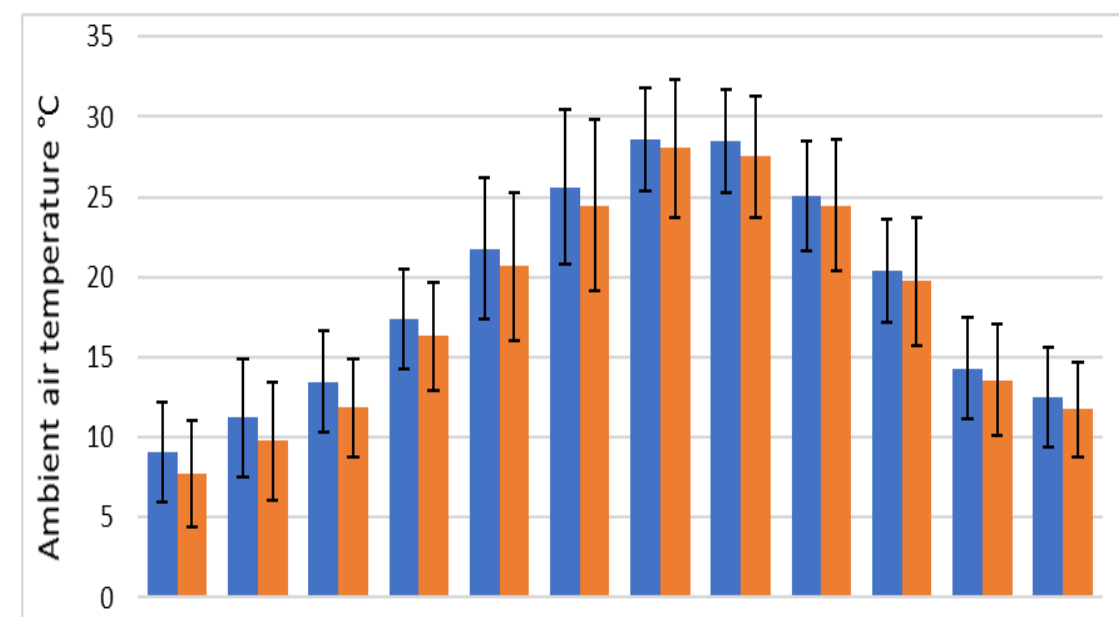

Jan. Feb. Mar. Apr. May Jun. Jul. Aug. Sep. Oct. Nov. Dec.

- Urban Rural

Figure 4 Average daily $(24 \mathrm{~h})$ ambient air temperatures $\left({ }^{\circ} \mathrm{C}\right)$ for each month for Patras and their standard deviation. 


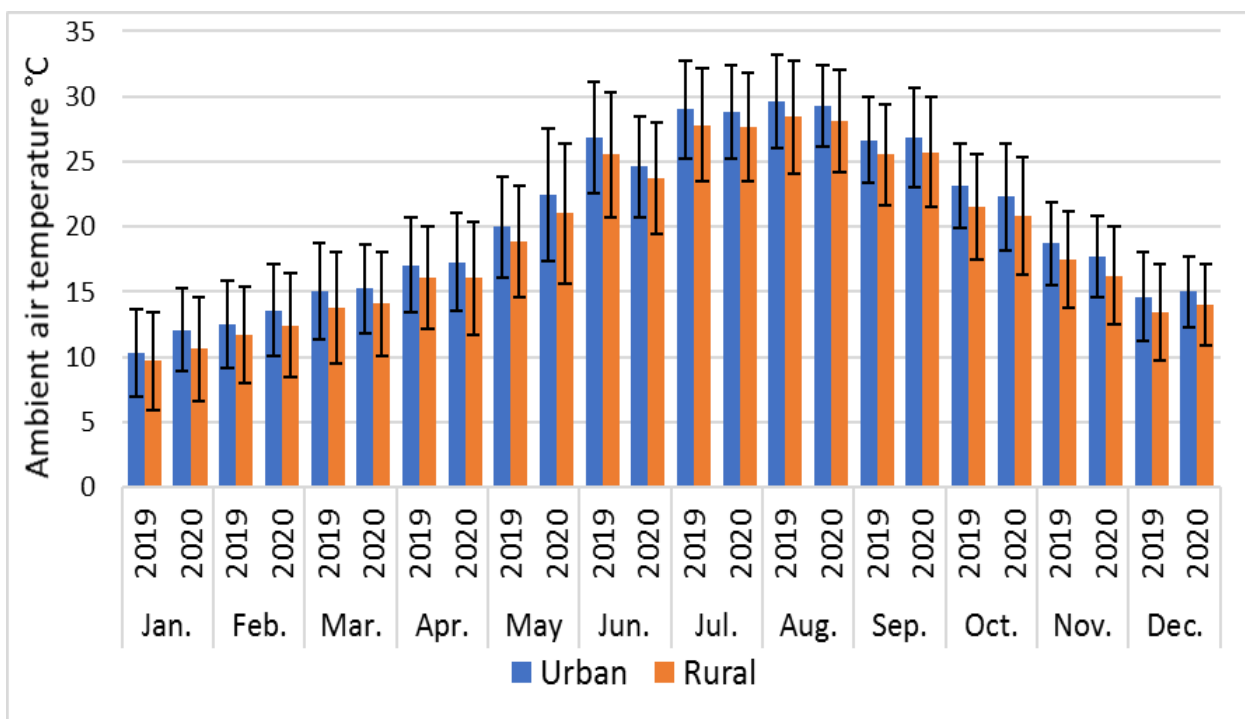

Figure 5 Yearwise average daily $(24 \mathrm{~h})$ ambient air temperature $\left({ }^{\circ} \mathrm{C}\right)$ for Kalamata for each month and their standard deviation.

The coldest month for Kalamata city is January, as evident from Tables 3 and 4 . This observation is also supported by the findings reported by TCG [11] and AUTh [21]. The comparison of the current study results with the findings of TCG [11] and AUTh [21] is shown in Table 8. It is also noted that 2019 was cooler than 2020 throughout the warmer months. The urban area of Kalamata has 5,178.14 HDHs lesser than the rural areas, accounting for a reduction of 24\% (Tables 3 and 4) and $1,489.86 \mathrm{CDH}$ s greater than the rural areas accounting for an increase of 22\% (Tables 5 and 6 ). These figures show the presence of a UHI effect in Kalamata, which is stronger than in Patras. August tends to be the warmest month in agreement with TCG [11] and in contrast with AUTh [22], which records July as the warmest month (Table 9). During the cooling phase, it was also noticed that 2019 was warmer than 2020. Figures 4 and 5 show the average daily (24 h) ambient air temperatures for each month and their standard deviations for Patras and Kalamata, respectively, providing a clear depiction of the typical air temperature conditions prevailing in the study area. From Tables 3, 4, 5, and 6, it appears that 2020 was warmer during the heating phase and colder during the cooling phase when compared with 2019.

The difference in HDHs and CDHs between the urban and rural areas of the two cities reflect an index of energy consumption. However, these differences may not be real, as it depends on the characteristics of each building, such as type of use, operation schedules, number of people, etc., and the variation profiles of ambient temperature.

\subsection{Comparisons with Records from Other Sources}

As part of the study, the estimated data were compared with the findings reported by TCG and AUTh [11, 21, 22]. The AUTh [21, 22] provides HDD and CDD monthly average values based on mean monthly temperature data for Patras and Kalamata during a range of consecutive years spanning from 1955 to 1997 in Patras and 1956 to 1997 in Kalamata. TCG [11] reported HDD values for both the cities and $\mathrm{CDH}$ values for only the Kalamata city. Historical data has been included with ambiguous sources and temporal periods, particularly before 2003. Temperature data were procured from the Hellenic National Meteorological Service (HNMS) [25], and its surface stations 
for Patras and Kalamata are WMO 689 (Lat. 38 $15^{\prime} \mathrm{N}$; Long. $21^{\circ} 44^{\prime} \mathrm{E}$; Elevation $3 \mathrm{~m}$ ) and WMO 726 (Lat. $37^{\circ} 04^{\prime} \mathrm{N}$; Long. $22^{\circ} 01^{\prime} \mathrm{E}$; Elevation $8 \mathrm{~m}$ ), respectively. The surface station in Kalamata is located at the airport, in a distinctly rural inland area $\sim 4 \mathrm{~km}$ from the inland rural reference station and $\sim 5$ $\mathrm{km}$ from the coastline. The surface station in Patras is situated at the central jetty of the old port, directly along the coastline and near to the city center. The station receives a positive influence due to its direct proximity to the sea.

Table 7 Comparisons of estimated HDDs and CDDs for Patras with other source data [11, $21,22]$.

\begin{tabular}{llllllll}
\hline & HDDs & & & & CDDs & & \\
Source & P.W.-U & P.W.-R & AUTh & TCG & P.W.-U & P.W.-R & AUTh \\
Month & & & & & & & \\
\hline January & 272.86 & 316.83 & 251 & 248 & - & - & - \\
February & 188.85 & 228.75 & 210 & 207 & - & - & - \\
March & 142.92 & 191.96 & 178 & 171 & - & - & - \\
April & 47.58 & 72.71 & 92 & 72 & 0.25 & 0.32 & - \\
May & 13.52 & 23.62 & 45 & - & 13.87 & 10.63 & - \\
June & 0.52 & 2.65 & - & - & 54.32 & 46.72 & 17 \\
July & - & - & - & - & 91.27 & 86.38 & 45 \\
August & - & - & - & - & 87.25 & 70.89 & 50 \\
September & 0.25 & 1.48 & - & - & 29.29 & 31.66 & 13 \\
October & 12.91 & 22.03 & 32 & - & 1.95 & 6.65 & - \\
November & 114.08 & 137.50 & 119 & 105 & 0.04 & - & - \\
December & 169.40 & 194.37 & 210 & 205 & - & - & - \\
Yearly & $\mathbf{9 6 2 . 9 0}$ & $\mathbf{1 , 1 9 1 . 8 9}$ & $\mathbf{1 , 1 3 7}$ & $\mathbf{1 , 0 0 8}$ & $\mathbf{2 7 8 . 2 2}$ & $\mathbf{2 5 3 . 2 5}$ & $\mathbf{1 2 5}$ \\
\hline
\end{tabular}

Table 8 Comparisons of estimated HDDs for Kalamata with other source data [11, 21].

\begin{tabular}{lllll}
\hline & \multicolumn{1}{l}{ HDDs } & & \\
Source/ & P.W.-U & P.W.-R & AUTh & TCG \\
Month & & & \\
\hline January & 211.95 & 243.27 & 245 & 242 \\
February & 145.51 & 171.76 & 210 & 207 \\
March & 104.02 & 137.09 & 184 & 177 \\
April & 59.32 & 85.94 & 101 & 84 \\
May & 15.79 & 33.40 & 49 & - \\
June & 0.85 & 4.72 & - & - \\
July & - & - & - & - \\
August & - & - & - & - \\
September & - & 0.47 & - & - \\
October & 3.07 & 18.97 & 33 & - \\
November & 34.89 & 66.24 & 111 & 96 \\
\hline
\end{tabular}




\begin{tabular}{lllll}
\hline December & 106.18 & 135.48 & 201 & 198 \\
Yearly & $\mathbf{6 8 1 . 5 8}$ & $\mathbf{8 9 7 . 3 3}$ & $\mathbf{1 1 3 4}$ & $\mathbf{1 0 0 4}$ \\
\hline
\end{tabular}

Table 9 Comparisons of CDDs and CDHs for Kalamata with other source data [11, 22].

\begin{tabular}{lllllll}
\hline & CDDs & & & CDHs & \\
Source & P.W.-U & P.W.-R & AUTh & P.W.-U & P.W.-R & TCG \\
Month & & & & & & \\
\hline January & - & - & - & - & - & - \\
February & - & - & - & - & - & - \\
March & 0.01 & - & - & 0.24 & - & - \\
April & 0.95 & 0.49 & - & 22.78 & 11.83 & - \\
May & 15.43 & 11.53 & - & 370.34 & 276.79 & - \\
June & 48.00 & 38.60 & 17 & $1,151.88$ & 926.34 & 461 \\
July & 100.64 & 84.43 & 44 & $2,415.45$ & $2,026.28$ & 1,146 \\
August & 110.93 & 94.32 & 43 & $2,662.23$ & $2,263.74$ & 1,130 \\
September & 55.06 & 45.21 & 11 & $1,321.38$ & $1,085.00$ & 187 \\
October & 13.39 & 7.89 & - & 321.42 & 189.45 & - \\
November & 0.24 & 0.09 & - & 5.80 & 2.22 & - \\
December & - & - & - & - & - & - \\
Yearly & $\mathbf{3 4 4 . 6 5}$ & $\mathbf{2 8 2 . 5 7}$ & $\mathbf{1 1 5}$ & $\mathbf{8 , 2 7 1 . 5 1}$ & $\mathbf{6 , 7 8 1 . 6 5}$ & $\mathbf{2 , 9 2 4}$ \\
\hline
\end{tabular}

Any positive or negative estimates cannot be based on the agreement or disagreement between the observed and published findings in the study area. Data from several recent years must be processed to accomplish this, even though certain complications may arise. Tables 10, 11, and 12 show the associations derived from the observed values in the present study and the values for urban areas, rural areas, an average of urban as well as rural areas, values from the AUTh [21, 22] and TCG [11] are represented in the tables as PW, PWU, PWR, PWUR, AUTh, and TCG respectively. For Patras city, the associations derived for annual values are given in Table 10.

Table 10 The associations derived for the annual values for the Patras city.

\begin{tabular}{|c|c|c|c|}
\hline$H D D_{P W U}=0.85 H D_{A U T h}$ & (C1) & $\mathrm{HDD}_{\mathrm{PWU}}=0.96 \mathrm{HDD}_{\mathrm{TCG}}$ & (C2) \\
\hline$H_{\text {PDWR }}=1.05 \mathrm{HDD}_{\text {AUTh }}$ & (C3) & $\mathrm{HDD}_{\mathrm{PWR}}=1.18 \mathrm{HDD}_{\mathrm{TCG}}$ & (C4) \\
\hline$H D D_{\text {PWUR }}=0.95 H D_{\text {AUTh }}$ & (C5) & $\mathrm{HDD}_{\mathrm{PWUR}}=1.07 \mathrm{HDD}_{\mathrm{TCG}}$ & (C6) \\
\hline$C D D_{P W U}=2.23 C D_{A U T h}$ & (C7) & $\mathrm{CDD}_{\mathrm{PWR}}=2.03 \mathrm{CDD}_{\mathrm{AUTh}}$ & (C8) \\
\hline$C D D_{P W U R}=2.13 C_{\text {AUTh }}$ & (C9) & & \\
\hline
\end{tabular}

A considerable variation could be observed in the CDDs estimated in the present study and those reported by TCG and AUTh [11, 22]. CDDPW is found to be more than double those of the TCG and 
AUTh. However, this deviation could not be observed for HDD values, instead considered normal. The AUTh values were extracted from the HNMS station, and hence HDDPWR values are slightly higher (relation (C3)) due to the positive influence of coastline to the HNMS station. The same fact explains the relation (C4) if TCG values are extracted from HNMS data stations as AUTh, but for different years. However, the values of CDDPwu and CDDPWR (more than twice of AUTh value), relations (C7) and (C8) are difficult to explain due to the impact of the sea on the HNMS measurement station. For Kalamata city, the association derived for annual values is shown in Table 11 and 12 .

Table 11 The associations derived for the annual values of HDD for the Kalamata city.

\begin{tabular}{|c|c|c|c|}
\hline$H D D_{P W U}=0.6 H_{D D} D_{\text {AUTh }}$ & (C10) & $H_{P W U}=0.68 \mathrm{HDD}_{T C G}$ & (C11) \\
\hline$H D_{\text {PWR }}=0.79 H \mathrm{HDD}_{\text {AUTh }}$ & (C12) & $\mathrm{HDD}_{\mathrm{PWR}}=0.89 \mathrm{HDD}_{\mathrm{TCG}}$ & (C13) \\
\hline$H_{\text {PWUR }}=0.7 \mathrm{HDD}_{\text {AUTh }}$ & (C14) & $\mathrm{HDD}_{\mathrm{PWUR}}=0.79 \mathrm{HDD}_{\mathrm{TCG}}$ & (C15) \\
\hline
\end{tabular}

HDD ${ }_{P W}$ is always smaller than $\mathrm{HDD}_{\mathrm{AUTh}}$ and $\mathrm{HDD}_{\mathrm{TCG}}$, with fluctuations of $60 \%$ and $89 \%$.

Table 12 The associations derived for the annual values of CDD and CDH for the Kalamata city.

\begin{tabular}{|llll|}
\hline $\mathrm{CDD}_{\mathrm{PWU}}=3 \mathrm{CDD}_{\text {AUTh }}$ & $(\mathrm{C} 16)$ & $\mathrm{CDD}_{\mathrm{PWR}}=2.46 \mathrm{CDD}_{\mathrm{AUTh}}$ & $(\mathrm{C} 17)$ \\
$\mathrm{CDD}_{\mathrm{PWUR}}=2.73 \mathrm{CDD}_{\text {AUTh }}$ & $(\mathrm{C} 18)$ & $\mathrm{CDH}_{\mathrm{PWU}}=2.83 \mathrm{CDH}_{\mathrm{TCG}}$ & $(\mathrm{C} 19)$ \\
$\mathrm{CDH}_{\text {PWR }}=2.32 \mathrm{CDH}_{\text {TCG }}$ & $(\mathrm{C} 20)$ & $\mathrm{CDH}_{\text {PWUR }}=2.57 \mathrm{CDH} \mathrm{H}_{\mathrm{TCG}}$ & $(\mathrm{C} 21)$ \\
\hline
\end{tabular}

$C D D_{P W}$ is significantly higher than $\mathrm{CDD}_{\mathrm{AUTh}}$, attaining a value three times that of $\mathrm{CDD}_{\mathrm{AUTh}}$ and a similar principle applies to $\mathrm{CDH}_{\mathrm{PW}}$ to a lesser extent.

The following observations are established after the abovementioned analysis and the fact that AUTh and TCG are used as major sources of the recent historical data in this study. Comparisons with TCG sources are not taken into account, as the measurement reference stations are unknown. As the HNMS measurement station in the Kalamata city is situated in rural area, the data collected from this station are compared with the results obtained from the local rural stations considered for this study. The same will be done for Patras due to the positive influence of the sea on the data collected by HNMS station even though it is located close to the city.

It should also be noted that no extreme weather events could be observed in the study area during the years 2018, 2019, and 2020 [25]. The comparably higher observed CDDPWR values for Patras and Kalamata as compared to the $\mathrm{CDD}_{\text {AUTh }}$ (relations (C8), (C17)) indicate a warmer summer

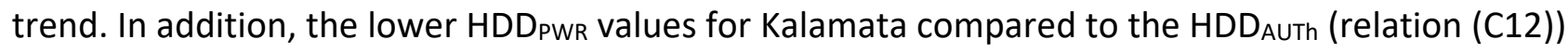
indicate a modest tendency for warmer winters. As previously demonstrated and confirmed by the relations (C1) and (C5), the slightly opposite conclusion of the relation (C3) seems to have no effect on the depiction. Furthermore, the inclusion of two rural stations in different places helps to clarify the comparisons made in the Kalamata city. These findings are consistent with the conclusions of Spinoni et al. [14] and other Mediterranean-related research. However, the constraint that an 
update of DHs and DDs, for the entire country and separately for each urban and rural area appears to be required.

\section{Conclusions}

The hourly ambient air temperature data of Patras city were collected annually for 2018, and that of Kalamata city were collected for the years 2019 and 2020. For both these cities, data has been compiled to determine the heating and cooling degree hours. The conclusions derived from the results of this study are as follows.

\subsection{For Patras City}

The urban and rural HDHs in Patras city amount to $23,109.51$ and 28,605.40, respectively, with a reduction of $19.2 \%$ in urban $\mathrm{HDH}$ s relative to rural $\mathrm{HDHs}$. Similarly, the urban and rural $\mathrm{CDHs}$ amount to $6,677.33$ and $6,078.10$, respectively, with an increase of $9 \%$ in urban areas compared to the rural areas.

\subsection{For Kalamata City}

The urban and rural HDHs amount to $16,357.80$ and $21,535.94$, with a $24 \%$ reduction in urban $\mathrm{HDH}$ relative to rural HDHs. Similarly, the urban and rural CDHs amount to 8,271.51 and 6,781.65, respectively, a $22 \%$ rise in the urban zones.

In both the cities, a UHI effect could be observed with more intensity reported in Kalamata. The observed data were compared with the findings published by other researchers [11, 21, 22]. There is a slight tendency towards milder winters and warmer summers, which needs more extensive investigation.

More precise data collection methods and devices are required due to climate change and the discrepancies among the supplied by different sources [11, 21, 22]. There are several reliable weather stations at a reasonable price available nowadays, which can be installed in urban, suburban, and rural areas to gather accurate meteorological data (hourly at least). Data collected for several years may be used in comprehensive and simplified energy calculation approaches for independently treating urban, suburban, and rural areas.

\section{Author Contributions}

P. Kyriakopoulos has collected and elaborated the data for Kalamata. Also, he has written a part of this work. A. Giannopoulos has collected and elaborated the data for Patras. Y. Caouris has supervised this work. M. Souliotis and M. Santamouris were occupied with the validation of results.

\section{Competing Interests}

The authors have declared that no competing interests exist.

\section{References}

1. Papakostas K, Tsilingiridis G, Kyriakis N. Bin weather data for 38 Greek cities. Appl Energy. 2008; 85: 1015-1025. 
2. Papakostas KT. Technical note Bin weather data of Athens, Greece. Renew Energy. 1999; 17: 265-275.

3. Bulut H, Büyükalaca O, Yılmaz T. Bin weather data for Turkey. Appl Energy. 2001; 70: 135-155.

4. Matzarakis A, Thomsen F. Heating and cooling degree days as an indicator of climate change in Freiburg [Internet]. Freiburg: University of Freiburg; 2008. Available from: https://www.researchgate.net/publication/237533426 HEATING AND COOLING DEGREE D AYS AS AN INDICATOR OF CLIMATE CHANGE IN FREIBURG.

5. Assawamartbunlue K. An investigation of cooling and heating degree-hours in Thailand. J Clean Energy Technol. 2013; 1: 87-90.

6. Papakostas K, Kyriakis N. Heating and cooling degree-hours for Athens and Thessaloniki Greece. Renew Energy. 2005; 30: 1873-1880.

7. ASHRAE. Climatic data for building design standards [Internet]. Atlanta: ASHRAE; 2013. Available from: https://xp20.ashrae.org/standard169/169 2013 a 20201012.pdf.

8. Harvey LD. Using modified multiple heating-degree-day (HDD) and cooling-degree-day (CDD) indices to estimate building heating and cooling loads. Energy Build. 2020; 229: 110475.

9. Mourshed M. Relationship between annual mean temperature and degree-days. Energy Build. 2012; 54: 418-425.

10. Shin M, Do SL. Prediction of cooling energy use in buildings using an enthalpy-based cooling degree days method in a hot and humid climate. Energy Build. 2016; 110: 57-70.

11. Technical Chamber of Greece. Technical guideline 20701-3/2010 [Internet]. Athína: Technical Chamber of $\quad$ Greece; $2014 . \quad$ Available from: http://portal.tee.gr/portal/page/portal/SCIENTIFIC WORK/GR ENERGEIAS/kenak/files/TOTEE 20701-3 2010 TEE 3nd Edition.pdf.

12. Moustris KP, Nastos PT, Bartzokas A, Larissi IK, Zacharia PT, Paliatsos AG. Energy consumption based on heating/cooling degree days within the urban environment of Athens, Greece. Theor Appl Climatol. 2015; 122: 517-529.

13. Letherman KM, Al-Azawi MM. Predictions of the heating and cooling energy requirements in buildings using the degree hours method. Build Environ. 1986; 21: 171-176.

14. Spinoni J, Vogt JV, Barbosa P, Dosio A, McCormick N, Bigano A, et al. Changes of heating and cooling degree-days in Europe from 1981 to 2100. Int J Climatol. 2018; 38: e191-e208.

15. Andrade $C$, Mourato $S$, Ramos J. Heating and cooling degree-days climate change projections for Portugal. Atmosphere. 2021; 12: 715.

16. Ramon D, Allacker K, De Troyer F, Wouters H, van Lipzig NP. Future heating and cooling degree days for Belgium under a high-end climate change scenario. Energy Build. 2020; 216: 109935.

17. Pachauri RK, Meyer LA. Climate change 2014: Synthesis report [Internet]. Geneva: Intergovernmental Panel on Climate Change; 2014. Available from: https://www.ipcc.ch/site/assets/uploads/2018/05/SYR AR5 FINAL full wcover.pdf.

18. Diffenbaugh NS, Giorgi F. Climate change hotspots in the CMIP5 global climate model ensemble. Clim Change. 2012; 114: 813-822.

19. Giannakopoulos C, Kostopoulou E, Varotsos KV, Tziotziou K, Plitharas A. An integrated assessment of climate change impacts for Greece in the near future. Reg Environ Change. 2011; 11: 829-843.

20. Diffenbaugh NS, Pal JS, Giorgi F, Gao X. Heat stress intensification in the Mediterranean climate change hotspot. Geophys Res Lett. 2007; 34: L11706. 
21. Papakostas K, Tsilingiridis G, Kyriakis N. Heating degree-days for 50 Greek cities. Tech Chron Sci J TCG. 2005; 4: 51-65.

22. Papakostas K, Tsilingiridis G, Kyriakis N. Cooling degree-days for 50 Greek cities. Tech Chron Sci J TCG. 2010; 1: 161-174.

23. Erbs DG, Beckman WA, Klein SA. Estimation of degree-days and ambient temperature bin data from monthly-average temperatures. ASHRAE J. 1983; 25: 60-65.

24. Caouris YG, Giannopoulos A, Santamouris M. Heating demands differences between central and surrounding areas in the coastal town of Patras. In: Proceedings of the International Conference Passive and Low Energy Cooling 2005. Santorini: Heliotopos Conferences; 2005. pp.139-143.

25. Hellenic National Meteorological Service. Homepage [Internet]. Elliniko: Hellenic National Meteorological Service. Available from: http://www.emy.gr/.

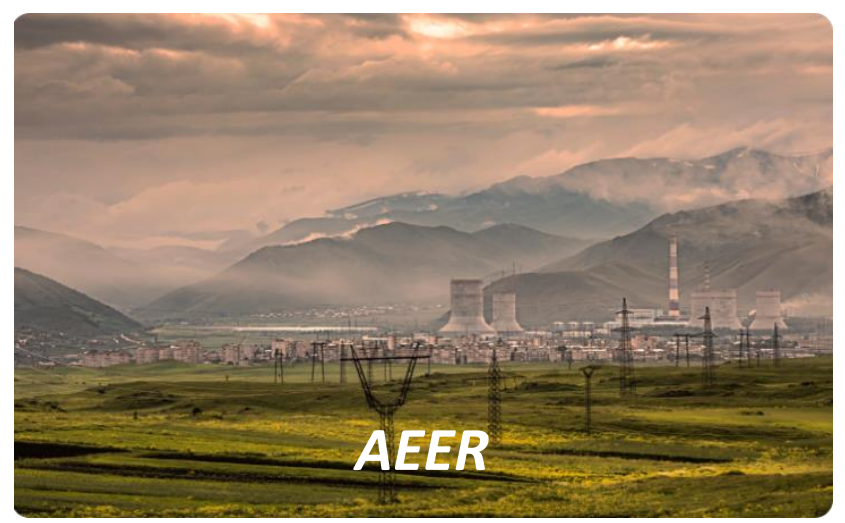

Enjoy AEER by:

1. Submitting a manuscript

2. Joining in volunteer reviewer bank

3. Joining Editorial Board

4. Guest editing a special issue

For more details, please visit:

http://www.lidsen.com/journals/aeer 